\title{
LOS TEST DE ASOCIACIÓN Y EL ESTABLECIMIENTO DE RELACIONES ENTRE CONCEPTOS QUÍMICOS.
}

Fidel Antonio Cárdenas $\mathrm{S}^{1}$. Catalina Rodríguez $\mathrm{B}^{2}$ y Mónica A. Vera $\mathrm{J}^{3}$.

\author{
RESUMEN
}

En una investigación realizada en la Universidad Pedagógica Nacional, en la cual participaron 23 estudiantes de primer semestre y 22 de quinto semestre, pertenecientes al programa de diseño tecnológico, se utilizaron los test de asociación para escudriñar el establecimiento de relaciones entre conceptos químicos por parte de estos dos grupos de estudiantes. El análisis de los resultados obtenidos a partir de la aplicación de una prueba fundamentada en la asociación de términos, pares de términos y la propuesta de procedimientos de laboratorio, con posterioridad al establecimiento de categorías de análisis condujeron entre otras, a la conclusión de que tanto en primero como en quinto semestre se observa que los estudiantes presentan dificultad para escribir una frase alrededor del concepto solución sobresaturada y que en ambos casos para las categorías establecidas, los porcentajes de estudiantes ubicados en ellas no alcanzan el $50 \%$.

\section{ABSTRACT}

This paper describes an investigation carried out using association test. The investigation involved forty-five undergraduate students of technological studies, which, belonged to two different semesters. It was the main objective of the research to use word association test in order to analyze the type of relations built by students using chemical concepts. Analysis of the results led to the conclusion that both, first semester as well fifth semester students have difficulties to write meaningful relations around chemical concepts such as saturated solutions and chemical equilibrium and equilibrium constant.

\section{INTRODUCCIÓN}

Uno de los aspectos básicos en el aprendizaje de las ciencias hace relación con el establecimiento de relaciones entre conceptos. Con mucha frecuencia y quizá debido a la introducción temprana en la educación de una enseñanza por disciplinas, muchos estudiantes se preguntan si conceptos como el de densidad, masa, peso o incluso los asociados a los estados de la materia, que suelen ser tratados tanto en las clases de química como en las de física son los mismos, o si se trata de conceptos diferentes y por tanto pertenecientes a dos campos distintos de la ciencia.

Con el objetivo de estudiar y estimular el desarrollo de la capacidad de los estudiantes para establecer relaciones entre conceptos, recientemente se han venido introduciendo a las aulas de clase de química los test de asociación. De una parte han sido introducidos como una forma de evaluación y de otra como instrumento didáctico.

En el presente artículo se reportan los resultados provenientes de una investigación realizada en la Facultad de Ciencia y Tecnología de la Universidad Pedagógica Nacional durante el segundo período académico del 2002, a la cual estuvieron vinculados estudiantes de primero y quinto semestres de la carrera de Diseño Tecnológico. En

\footnotetext{
${ }^{1}$ Profesor Titular Departamento Química Universidad Pedagógica Nacional. cardenas@uni.pedagogica.edu.co

${ }^{2}$ Lic. en Química Universidad Pedagógica Nacional.

${ }^{3}$ Lic. en Química Universidad Pedagógica Nacional.
} 
realidad el estudio involucró estudiantes de primero y quinto semestres de todos los departamentos de la Facultad, pero para efectos de este texto solo se dará cuenta de los resultados obtenidos para el programa antes mencionado.

En general, el estudio tuvo como objetivo analizar la capacidad para establecer relaciones entre conceptos de química para los estudiantes de los semestres mencionados en el contexto de los nuevos planes de estudio mediante el análisis de la producción escrita de los estudiantes usando para tal efecto un test de asociación.

\section{LOS TEST DE ASOCIACIÓN COMO FORMA DE ESTABLECER LA CAPACIDAD PARA RELACIONAR CONCEPTOS}

En su expresión mas simple, un test de asociación de palabras consiste en solicitar a un estudiante o un grupo de estudiantes, escribir una frase alrededor de un término o un concepto perteneciente a un campo particular del saber humano, con el objeto de establecer el dominio conceptual que poseen o el tipo de relaciones que puede establecer. (Cárdenas y Montealegre, 2002).

Dependiendo de los intereses de los evaluadores, del objetivo de la evaluación, y del nivel de escolaridad de los estudiantes con los cuales se emplean los test de asociación puede presentar diferentes niveles de complejidad. En el nivel más sencillo, como ya se dijo, se solicita al estudiante escribir una frase con relación a un solo término o concepto. El siguiente nivel, es la elaboración de una frase con dos términos o conceptos y todavía en un nivel más complejo se solicita al estudiante o a un grupo, elaborar un texto escrito en donde relacionen tres o más conceptos. De esta manera, es posible incrementar la complejidad de los test y avanzar incluso a niveles en los cuales se solicite la asociación no solo de una serie de términos sino también de ideas. (Ladino Yolanda).

\section{LOS TEST DE ASOCIACIÓN Y EL APRENDIZAJE SIGNIFICATIVO}

La evaluación a partir de test de asociación de palabras o ideas es coherente con la concepción de aprendizaje significativo de Ausubel, en cuanto a que éste implica el establecimiento intencional de relaciones entre las ideas o conceptos ya existentes en la mente de los alumnos con los conceptos nuevos que se quiere aprender y sus expresiones son relaciones conceptuales en forma de proposiciones. (Ausubel D., 1978)

La potencialidad de los test de asociación, descritos muy someramente en los párrafos anteriores, para elucidar información acerca del aprendizaje significativo de conceptos, radica en que le permiten al alumno y al docente ir más allá de la evocación memorística de definiciones, para introducirse en la búsqueda de las relaciones que establece un ser humano entre dos o más conceptos o dos o más términos o ideas, en este caso de naturaleza científica. En efecto, los escritos de los estudiantes proveen información acerca de las relaciones de subordinación, correlación, inclusión o supraordenación, que estando presentes en la mente de los jóvenes se hacen explicitas en su producción escrita. Este fue el contexto en el cual se emplearon los test de asociación de palabras en este trabajo.

\section{METODOLOGÍA}

El trabajo objeto de este artículo se realizó con 45 participantes distribuidos así: 23 estudiantes de primer semestre y 22 estudiantes de quinto semestre. En las tablas 1 y 2 se presenta la distribución del número de estudiantes encuestados en relación con el 
número de estudiantes matriculados en el programa en el momento de hacer la investigación y la distribución de los participantes por género.

Tabla No. 1 número de estudiantes matriculados y encuestados.

\begin{tabular}{|c|c|c|c|}
\hline $\begin{array}{ll}\text { SEMESTRE } & \text { ESTUDIANTES } \\
\end{array}$ & MATRICULADOS & ENCUESTADOS & ENCUESTADOS \\
\hline PRIMERO & 45 & 23 & 51 \\
\hline QUINTO & 25 & 22 & 88 \\
\hline TOTAL & 70 & 45 & 64 \\
\hline
\end{tabular}

Tabla No. 2. Distribución por género de los participantes.

\begin{tabular}{|c|c|c|c|c|}
\hline SEMESTRE GENERO & FEMENINO & $\%$ & MASCULINO & $\%$ \\
\hline PRIMERO & 8 & 35 & 15 & 65 \\
\hline QUINTO & 4 & 18 & 18 & 82 \\
\hline TOTAL & 12 & 27 & 33 & 73 \\
\hline
\end{tabular}

La ejecución del proyecto implicó el diseño de un instrumento de recolección de información, un test de asociación, la aplicación del mismo a los estudiantes seleccionados para la investigación, la organización de la información y el correspondiente análisis de la misma.

\section{RESULTADOS Y ANÁLISIS DE RESULTADOS.}

Como puede verse en el anexo 1, la prueba estuvo integrada por tres partes de diferente complejidad, una de las cuales implicaba que los estudiantes diseñaran un procedimiento para la obtención y el reconocimiento del gas oxígeno en el laboratorio. En concordancia con la estructura de la prueba, para el análisis de los resultados se llevó a cabo el siguiente procedimiento: se tomó la información aportada por los alumnos y para cada pregunta se establecieron categorías de respuestas. Estas categorías se propusieron a partir de la misma información; hechas las categorías se establecieron las respectivas frecuencias de distribución y se procedió a su análisis como se describe a continuación.

\section{Primera pregunta.}

Las respuestas a esta pregunta se ubicaron en una primera categoría que corresponde a los estudiantes que recurren a una definición cuando se les solicita escribir una frase con los conceptos dados en la pregunta. Es una situación muy frecuente encontrar, que la primera aproximación que tienen muchos alumnos cuando se les solicita escribir un frase acerca de un término o concepto es recordar y escribir una definición memorizada previamente; por esta razón, es poco recomendable utilizar los test de asociación solo con un termino o concepto, cuando se emplean dos o mas conceptos la posibilidad de recordar definiciones de memoria se hace menor.

Figura 1. Porcentaje de estudiantes de primer y quinto semestre que recurren a una definición para cada uno de los conceptos inducidos en la primera pregunta. 


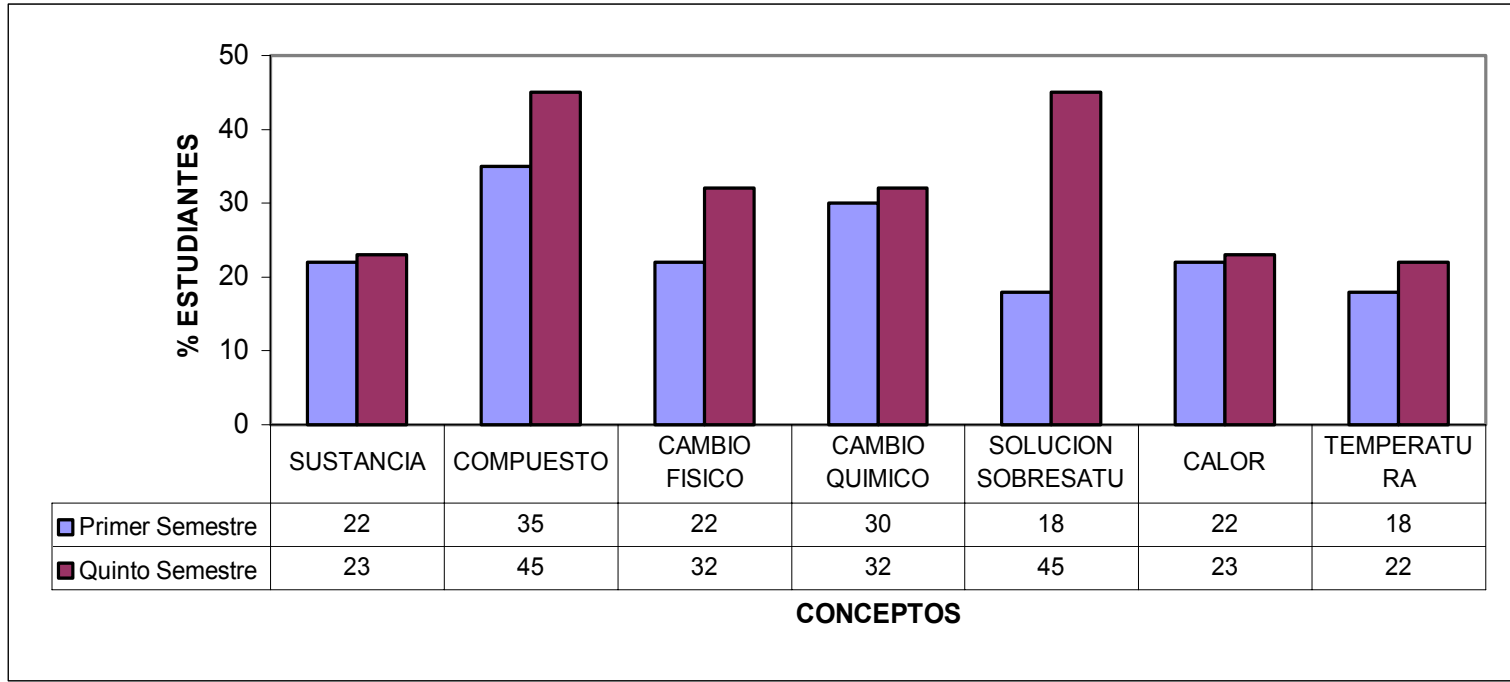

Como puede observarse en la figura 1, esta situación, de acudir a una definición, se presenta en un alto porcentaje tanto en estudiantes de primero como de quinto semestre, 35 y $45 \%$ respectivamente para el concepto de compuesto químico; en quinto semestre se destaca además el hecho que un $45 \%$ de los alumnos apela a una definición para el concepto de solución sobresaturada.

Llama la atención que en general, en ambos semestres, el número de estudiantes que acude a su memoria para relacionar los conceptos es superior al $20 \%$, esta es, sin mucha duda, una consecuencia de la práctica escolar y aún universitaria de asociar, con frecuencia, las evaluaciones con las definiciones.

En una segunda categoría se ubicaron las respuestas de los estudiantes que en sus frases incluyen un ejemplo relacionado con los conceptos de la pregunta. Los datos correspondientes a esta categoría se ilustran en la figura 2.

Figura 2. Porcentaje de estudiantes de primero y quinto semestres que hacen uso de ejemplos al elaborar sus frases para cada uno de los conceptos inducidos en la primera pregunta.

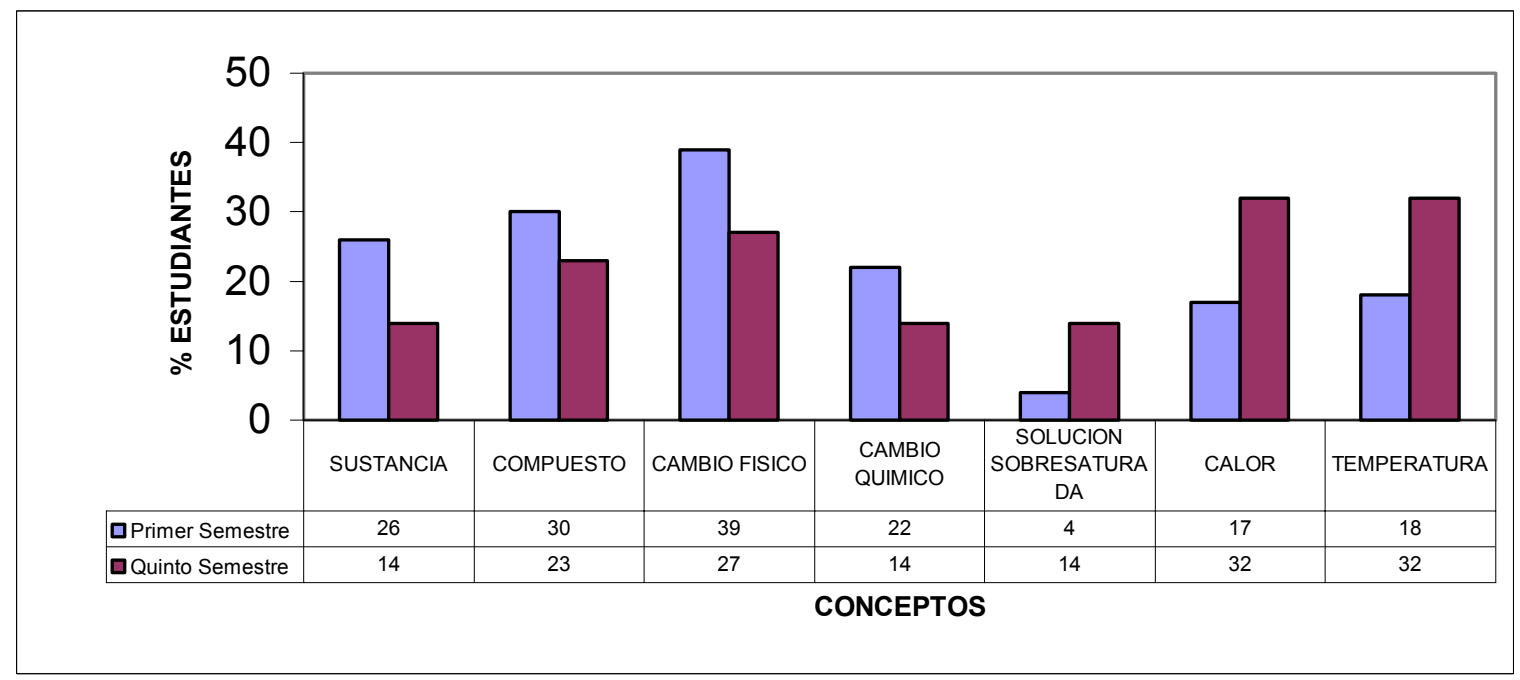

Es importante destacar en la figura 2, con referencia a esta categoría, que los porcentajes de estudiantes de primer semestre son mayores que los de quinto en los cuatro primeros conceptos de la pregunta, a partir de allí dominan los de quinto semestre. Los menores porcentajes de estudiantes que ilustran con ejemplos sus respuestas lo hacen para los 
conceptos de solución sobresaturada y calor y temperatura en primer semestre; siendo estudiantes de diseño tecnológico, estos resultados están de acuerdo a lo que podría esperarse, que aquellos alumnos de quinto semestre tengan mayor familiaridad con estos conceptos que los que apenas comienzan su carrera. Con respecto al concepto de solución sobresaturada, se observa que, el porcentaje es bajo con referencia a los demás conceptos, en efecto, este es uno de los tópicos que presentan mayor grado de dificultad para su aprendizaje. (Cárdenas Fidel, 2000).

En una tercera categoría se ubicaron las respuestas de los estudiantes que relacionan sus frases con la química para los conceptos dados en la pregunta. Estos datos se ilustran y se comentan a partir de la figura 3.

Figura 3. Porcentaje de estudiantes de primer y quinto semestres que hicieron relación a la química en sus frases elaboradas en los conceptos de la primera pregunta.

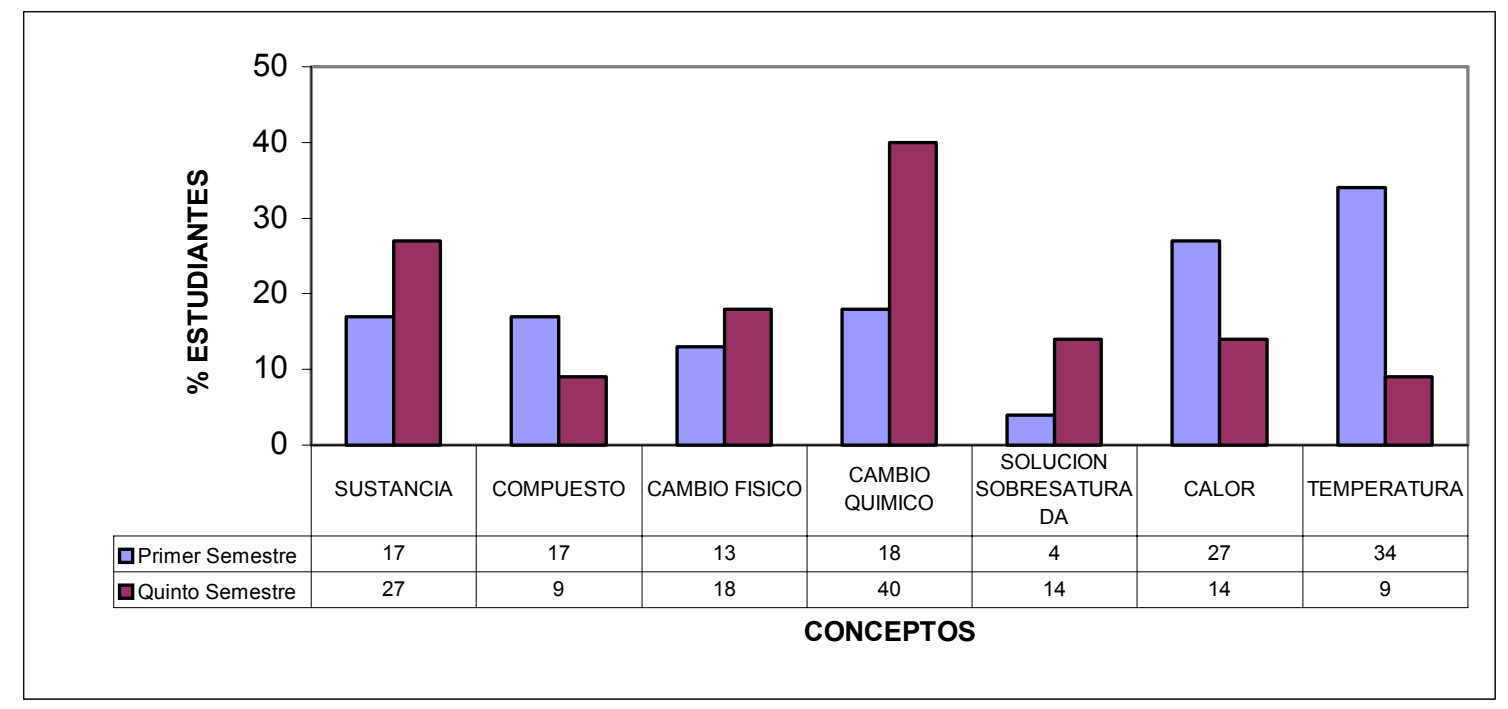

Para los estudiantes de primer semestre, el mayor porcentaje que relacionó sus frases con la química se concentra en los conceptos de calor y temperatura, con valores de $27 \%$ y $34 \%$ respectivamente. Para el mismo semestre, el menor porcentaje se ubica en el concepto de solución sobresaturada, 4\%; para los conceptos de sustancia, compuesto, cambio físico y cambio químico, los porcentajes de estudiantes se mantienen alrededor del $18 \%$ en este semestre.

El mayor porcentaje de estudiantes de quinto semestre, que relacionó con la química sus frases, se presenta en el concepto de cambio químico, seguido por el de sustancia química. En este mismo semestre, el menor porcentaje de estudiantes se encuentra en los conceptos de compuesto y temperatura con un $9 \%$ en los dos casos. Obsérvese además que en esta categoría, aún continúan los porcentajes de estudiantes bajos para el concepto de solución sobresaturada, no lo asocian con un evento químico.

En la cuarta categoría se hace mención a los estudiantes que no relacionaron sus frases con el ámbito de la química, como se ilustra y se analiza a partir de la figura 4. 
Figura 4. Porcentaje de estudiantes de primer y quinto semestre que no relacionan con la química sus frases con los conceptos de la primera pregunta.

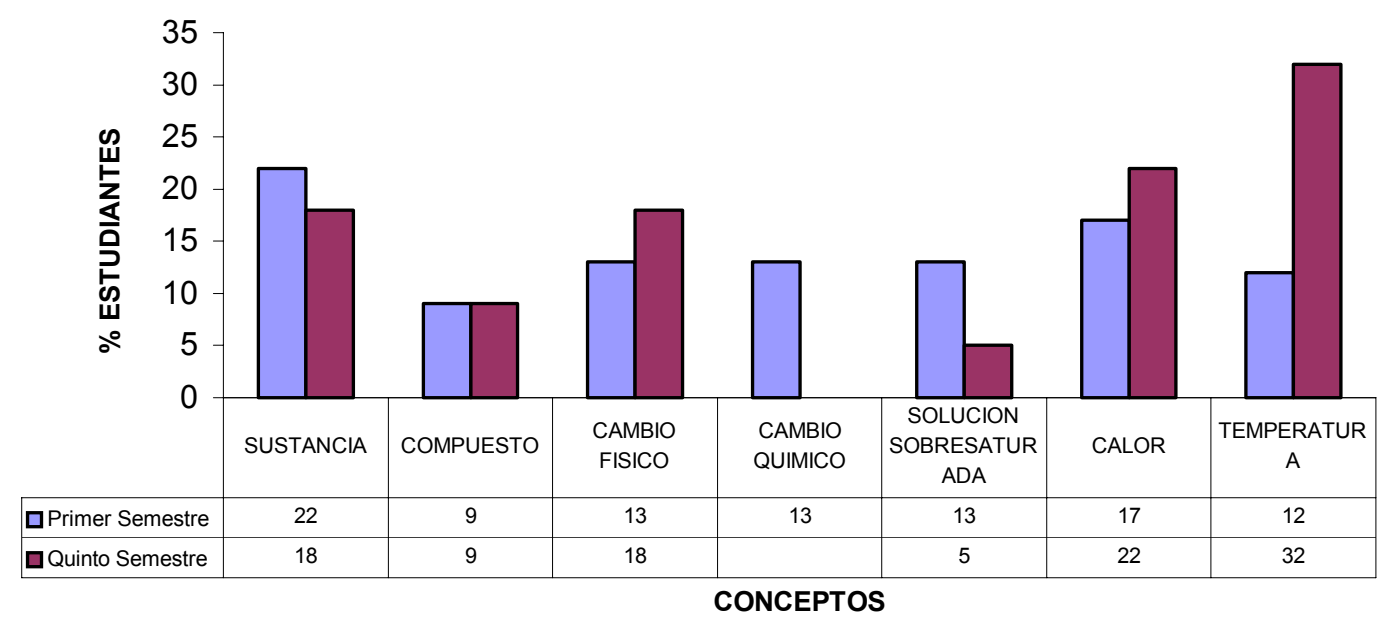

Comparados con los porcentajes de estudiantes ubicados en las categorías anteriores, en esta categoría se encuentra el menor porcentaje de ellos, su distribución en general es similar en todos los conceptos; para el caso de primer semestre, con una ligera excepción, en el de sustancia que es más alto. Al revisar los datos para quinto semestre, se observa que los porcentajes de estudiantes son bajos para solución sobresaturada, compuesto, e inexistentes para cambio químico.

Finalmente, en una quinta categoría se agruparon los estudiantes que no contestaron la pregunta, es decir, aquellos que no escribieron frase alguna acerca de los conceptos dados.

Figura 5. Porcentaje de estudiantes de primer y quinto semestres que no contestaron la primera pregunta.

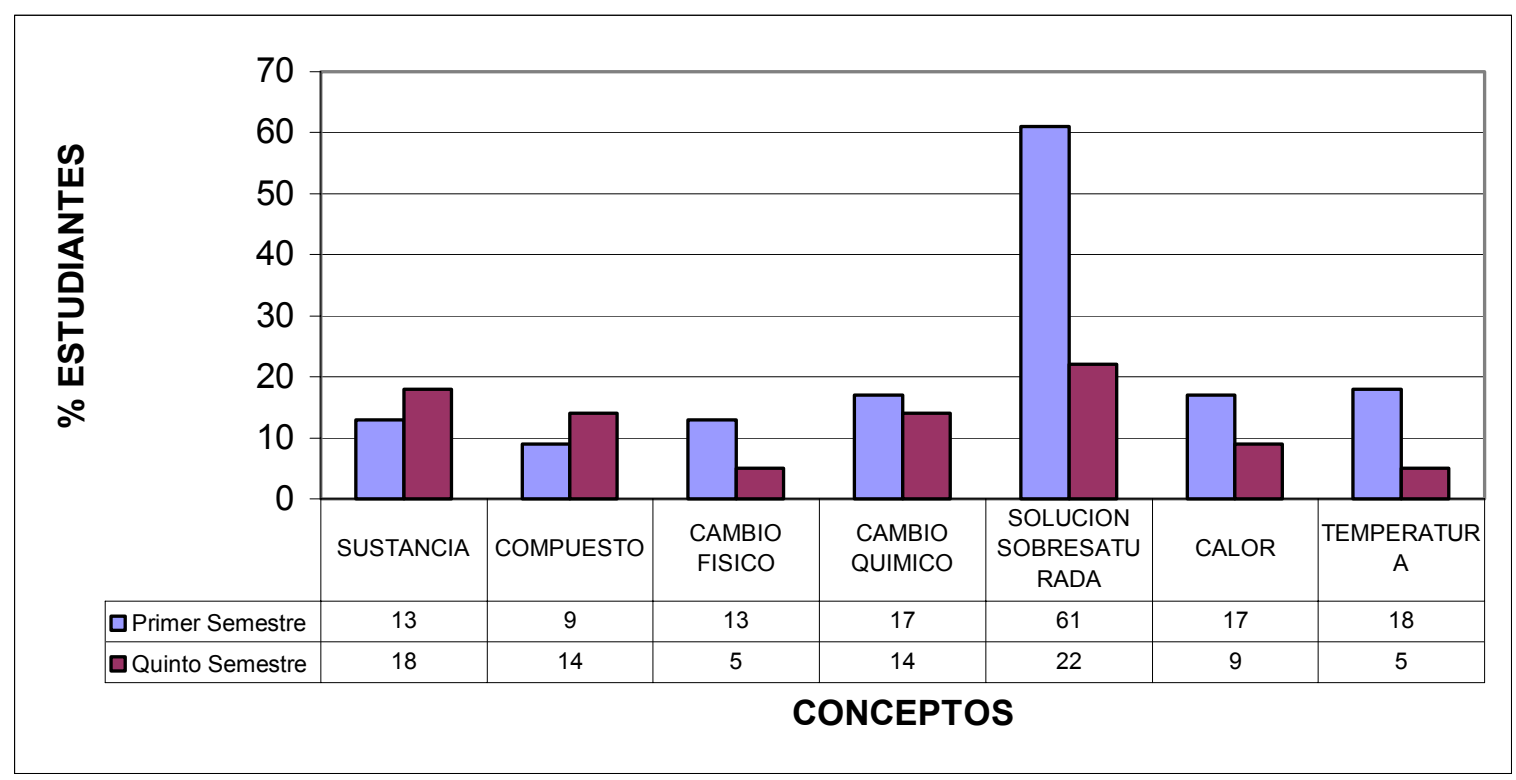

Como era de esperarse, en general en esta categoría están los porcentajes mas bajos de todas, con excepción del que hace relación al concepto de solución sobresaturada para ambos semestres; es importante resaltar que los porcentajes de primer semestre son relativamente altos para casi todos los conceptos de la pregunta; los estudiantes de quinto semestre en conceptos como sustancia, compuesto, cambio químico y calor, no 
contestaron en un porcentaje relativamente alto. Con todas las limitaciones de estas comparaciones estos datos son preocupantes, pueden interpretarse como un indicativo de que en la medida que los alumnos avanzan en los semestres de la carrera estos conceptos parecen irse olvidando. Idealmente, todos los estudiantes deberían dar respuesta a esta pregunta.

En resumen, la información dada por los estudiantes para esta primera pregunta se ubicó en cinco categorías y su distribución en porcentaje de estudiantes tiende a disminuir de la primera a la última.

\section{Segunda Pregunta.}

Las respuestas dadas por los estudiantes a esta pregunta se ubicaron también en categorías propuestas de manera semejante a las de la primera, como se describe a continuación.

En una primera categoría se ubicaron aquellos estudiantes que no dieron ninguna respuesta a esta pregunta.

Figura 6. Desempeño de los estudiantes de primero y quinto semestres del programa de Diseño Tecnológico, en términos de porcentaje de estudiantes que no contestaron la segunda pregunta.

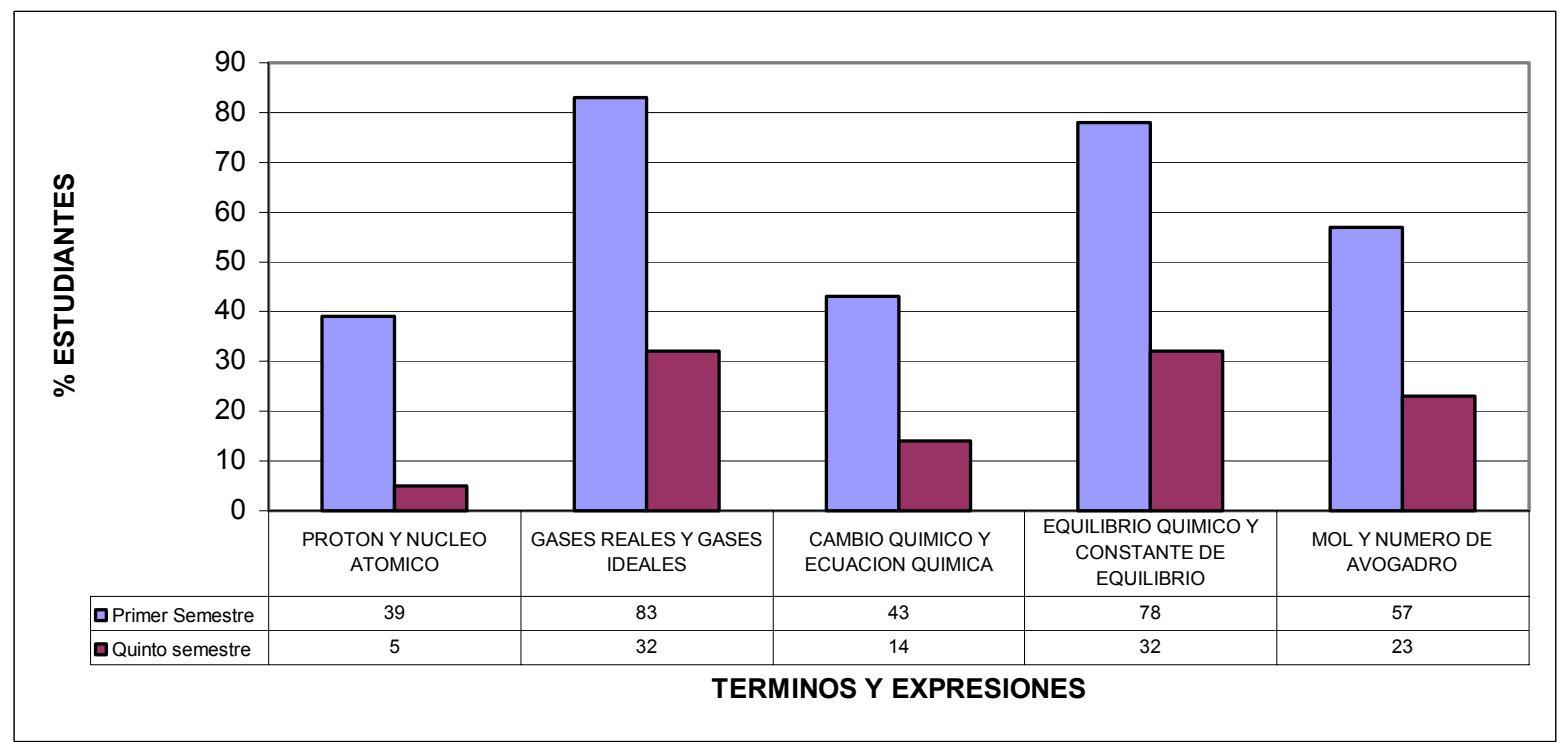

Frente a la solicitud de escribir una frase relacionando pares de términos dados, base de esta pregunta, para el primer semestre se observa que en tres de estos pares de términos: gases reales y gases ideales, cambio químico y constante de equilibrio y Mol y número de Avogadro, el porcentaje de estudiantes que no realizaron ninguna relación con ellos fue bastante alto, entre el 57 y el $83 \%$. Para el caso de los estudiantes de quinto semestre, los porcentajes de estudiantes que no dieron respuesta a esta pregunta son menores; sin embargo, los que hacen referencia al estado gaseoso y al equilibrio químico son relativamente altos como se puede ver en la figura 6.

Como se puede observa en la figura 7, el porcentaje de estudiantes que si elaboraron una frase relacionando los pares de témenos dados, esto es, que contestaron la pregunta en primer semestre, son menores con respecto a los correspondientes al quinto semestre; en efecto, mientras que en el segundo caso se alcanzan valores del $90 \%$ en los primero solo llegan a un $60 \%$. Tanto en el primero como en el quinto semestre, los pares de términos 
acerca de los cuales los porcentajes de estudiantes alcanzan los mayores porcentajes son los de protón y neutrón y cambio químico y ecuación química; una interpretación posible de estos resultados puede derivarse del hecho de que al analizar los delineamientos curriculares del Ministerio Educación Nacional estos temas están presentes a lo largo de toda la escuela secundaria, es decir, han sido objeto de estudio por los alumnos, una y otra vez, en el contexto de las ciencias naturales.

Figura 7. Desempeño de los estudiantes de primero y quinto semestres del programa de Diseño Tecnológico, en términos de porcentaje de estudiantes que contestaron la segunda pregunta.

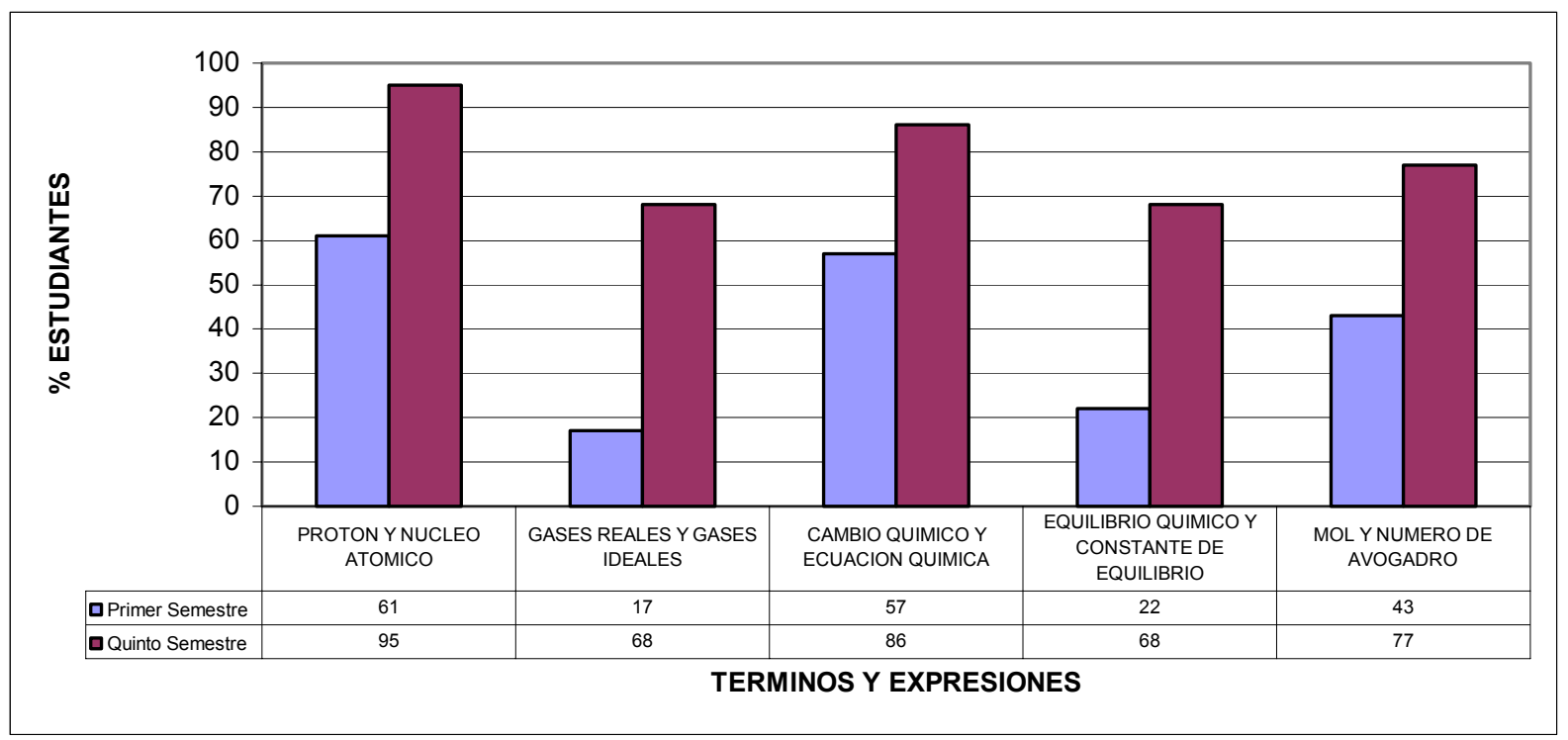

En una tercera categoría se han agrupado los estudiantes que hicieron una frase usando uno de los dos términos incluidos en la pregunta. Como se muestra en la figura 8, para el quinto semestre los porcentajes mas altos están asociados con los pares de términos cambio químico y ecuación química, equilibrio químico y constante de equilibrio y Mol y número de Avogadro.

En el primer semestre, en general, los datos son más bajos y se observa que el más alto corresponde al porcentaje relacionado con la pareja cambio químico y constante de equilibrio.

Figura 8. Porcentaje de estudiantes de primer o y quinto semestre del programa de Diseño Tecnológico que elaboraron una frase con uno de los dos términos incluidos en la segunda pregunta 


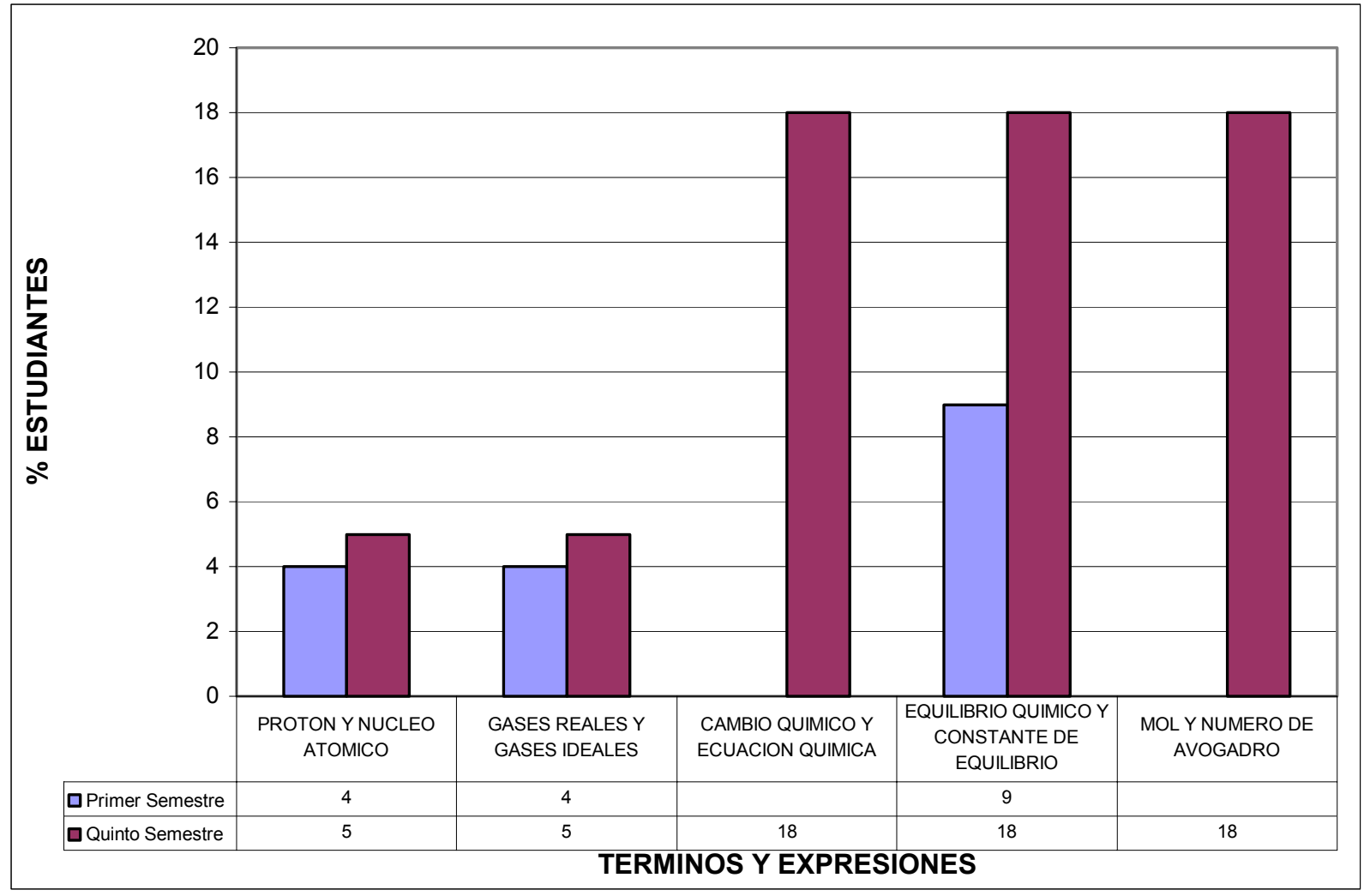

La cuarta categoría propuesta para analizar la información de esta pregunta de la prueba corresponde a aquellos estudiantes que, fieles a la solicitud, realizaron una frase empleando los dos términos dados en ella. Nótese que para dos de los cinco pares de términos, cambio químico y ecuación química y mol y número de avogadro, en primer semestre ninguno de los estudiantes encuestados relacionó, en la frase que elaboró, los dos términos.

Figura 9. Porcentaje de estudiantes de primero y quinto semestres del programa de Diseño Tecnológico que elaboraron una frase con los pares de términos de la segunda pregunta.

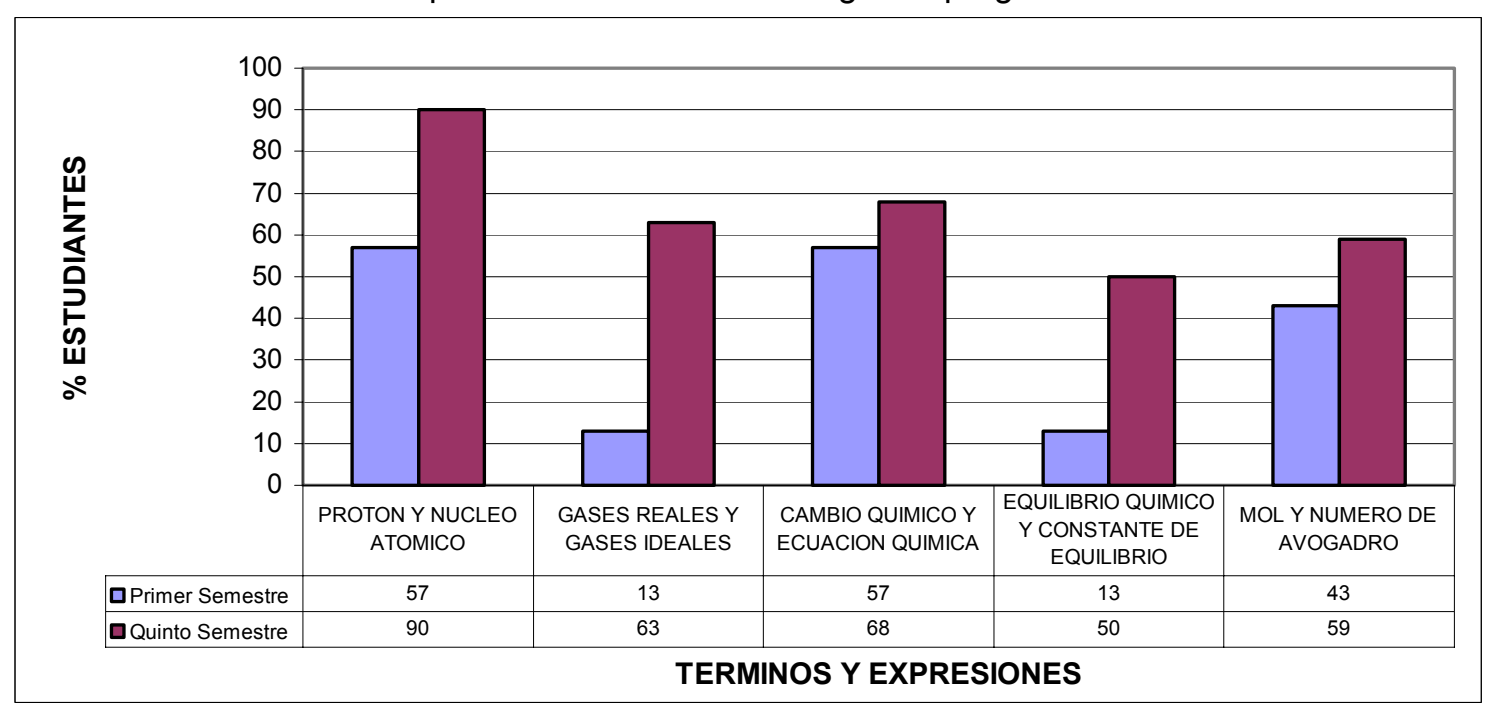

Con referencia al porcentaje de estudiantes que elaboraron frases relacionando los pares de términos dados en esta pregunta, se observa claramente que en el primer semestre, en tres de los cinco pares de términos: protón y núcleo atómico, cambio químico y ecuación química y Mol y Número de Avogadro los porcentajes son superiores al $40 \%$, mientras que para los otros dos pares estos valores apenas alcanzan al $10 \%$. En el caso de los estudiantes de quinto semestre se observa que en general los porcentajes, son 
superiores a los del primer semestre y que el mayor valor, 90\%, se presenta para el par de términos conformado por protón y núcleo atómico veáse figura No. 9.

Nótese que este porcentaje va descendiendo desde el par número uno hasta el par de Mol y Número de Avogadro, con alguna excepción. Esto podía atribuirse a que los pares equilibrio químico y constante de equilibrio y Mol y número de Avogadro son más complejos que los demás pares y por lo general no se abordan con suficiente profundidad en cursos introductorios de química.

Hay que anotar con respecto a esta pregunta, que se presenta bastante dificultad por parte de los estudiantes de primer semestre a la hora de construir una frase en la que relacionen los dos pares de términos, gases reales e ideales. Para los estudiantes de quinto semestre este ejercicio es mas facil, debido quizás a su formación académica, relacionada con la materia y sus propiedades físicas objeto de bastante trabajo en los estudios tecnológicos.

\section{Tercera Pregunta}

En esta pregunta se solicitaba a los estudiantes proponer un procedimiento práctico en el laboratorio para la obtención de oxígeno. Siguiendo los procedimientos anteriores para el análisis de las respuestas, en este caso, se han agrupado los estudiantes según hayan dado o no respuesta a la pregunta, es decir, si escribieron o no una alternativa de preparación del gas.

Como puede observarse en la figura 10, en ambos semestres el porcentaje de estudiantes que contestaron la pregunta fue mayor que el correspondiente a los que no lo hicieron y este valor es más alto para los estudiantes de primer semestre. En los estudiantes de quinto semestre el porcentaje de aquellos que no contestaron la pregunta supera el porcentaje de los correspondientes de primer semestre en 11 puntos. Así mismo, se observa que el porcentaje de alumnos que no contestaron la pregunta en ambos semestres es relativamente alto pero ligeramente mas altos en los de quinto semestre. Esta situación podría explicarse asumiendo que los estudiantes de Diseño electrónico no tienen mucha relación con los procedimientos químicos de laboratorio, o hace mucho tiempo que los estudiaron; mientras que los estudiantes de primer semestre pudieron haberlo trabajado más recientemente, o en años anteriores en sus estudios secundarios.

Figura 10. Porcentaje de estudiantes de primer y quinto semestre del programa de Diseño Tecnológico que contestaron y que no contestaron la tercera pregunta.

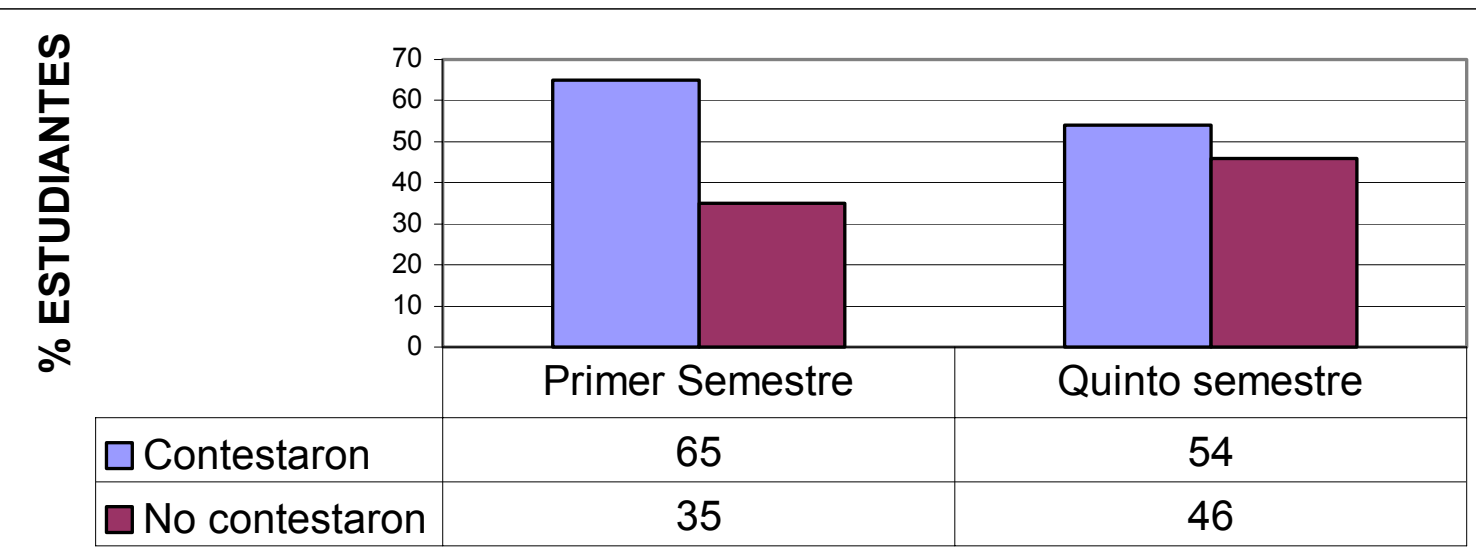

CATEGORIAS 


\section{La producción de textos escritos}

Como puede observarse en el anexo No. 1, el test de asociación aplicado estaba integrado por 4 preguntas, una de las cuales exigía escribir un texto relacionando tres variables tomando como base la lectura de un párrafo dado en el texto.

Esta pregunta abierta se utilizó para analizar la producción escrita de los estudiantes relacionando tres variables. Para la evaluación del establecimiento de relaciones entre variables por parte de los estudiantes, se propusieron cinco niveles de análisis, como se describe a continuación.

El nivel 0 corresponde a los estudiantes que no hicieron ningún tipo de producción escrita. El nivel A es apenas de naturaleza enunciativa, en el que el estudiante elabora una frase acerca de una de las variables o produce un texto poco pertinente con lo solicitado o simplemente reproduce el texto dado como base. En el nivel B se ubican textos que establecen una relación entre dos de las variables señaladas. En el nivel C, de mayor elaboración que los niveles anteriores, se organizan los textos que mencionan una o más relaciones entre las tres variables establecidas. Por último, en el nivel D se ubican los textos, mucho más elaborados en cuanto a las relaciones establecidas entre las tres variables y la forma en que sustenta sus ideas, poseen además un eje temático alrededor del cual se desarrolla una argumentación.

Con respecto a la producción escrita de textos, es importante resaltar que tanto en el primero como en el quinto semestres el mayor porcentaje de estudiantes se ubica en el nivel A. Este nivel corresponde a textos elaborados por alumnos en los cuales simplemente se enuncia una idea, no tienen argumentación, o hacen relacionan solamente una de las variables sin tener en cuenta las demás; también se encuentran, en este nivel, escritos como los que se ilustran a continuación, que son ambiguos o poco pertinentes a la temática de la pregunta.

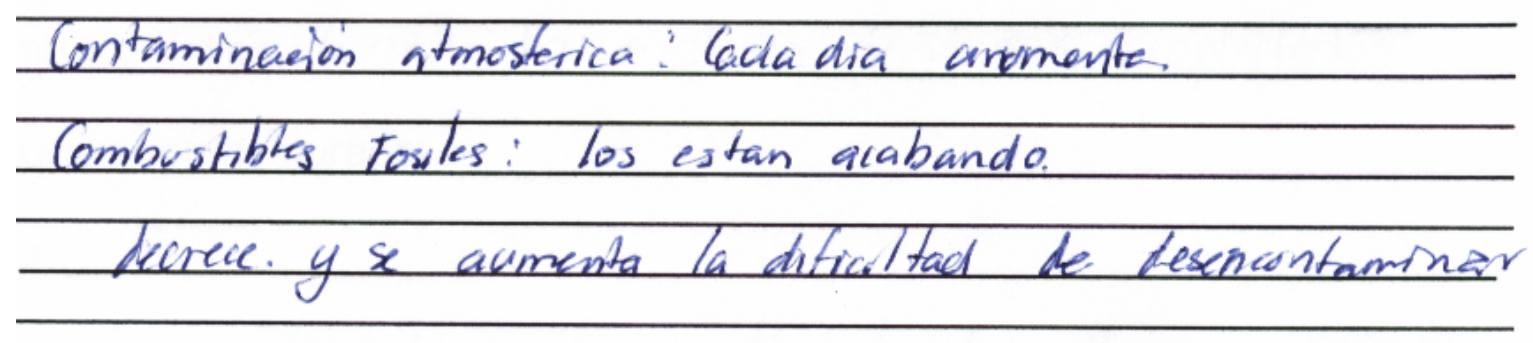

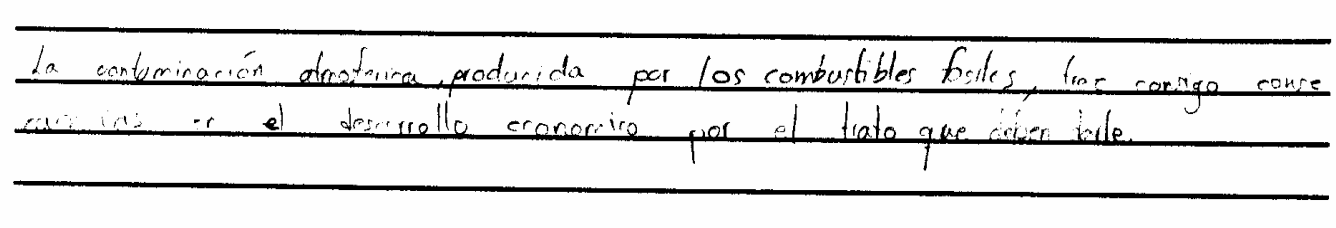

Figura 11. Porcentaje de estudiantes de primero y quinto semestre del programa de Diseño Tecnológico que se ubica en cada uno de los niveles propuestos para analizar la producción escrita. Cuarta pregunta. 


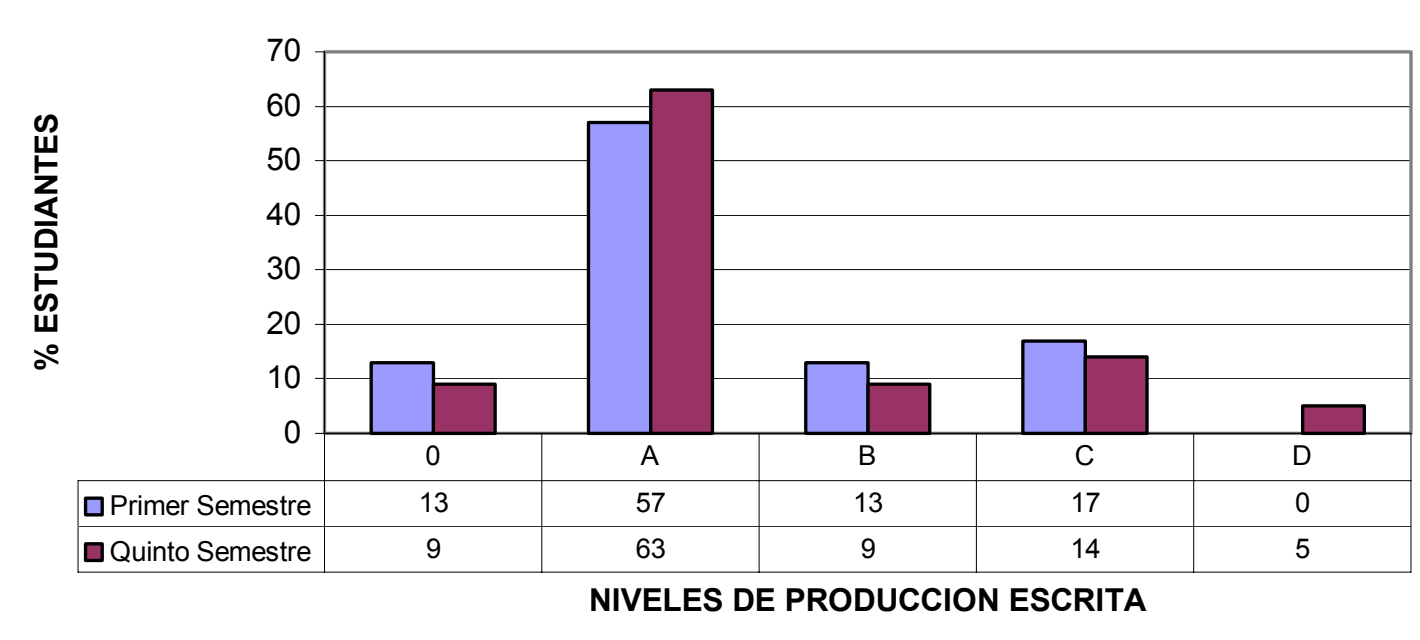

Para los estudiantes de primer semestre se puede observar en la figura 11, que ninguno de ellos se ubicó en el nivel $\mathrm{D}$, el de mayor elaboración y argumentación; en quinto semestre, por el contrario, el $5 \%$ de los estudiantes de este semestre alcanzó este nivel. En términos generales, son muy pocos los estudiantes que relacionaron dos o tres variables en sus escritos, los mayores porcentajes en estos casos se presentan en primer semestre, en oposición a lo que cabría esperarse, es decir, que fueran los estudiantes del semestre mas avanzado los que presentaran los mayores niveles de producción escrita.

Para mejorar la producción escrita, es indispensable establecer en el aula de clase un trabajo activo y permanente en la interpretación de textos científicos y la consiguiente elaboración de textos escritos a partir de ellos. La producción e interpretación de textos científicos, no sólo es una forma recomendable de evaluar, sino también de permitir el desarrollo de competencias básicas en la lengua materna, el uso adecuado de los conceptos y el establecimiento de relaciones entre ellos.

\section{CONCLUSIONES}

Los estudiantes de primer semestre del programa en mención presentan una alta tendencia a elaborar frases en las que hacen uso de ejemplos cuando, en un test de asociación, se les solicita elaborar una frase con un grupo de conceptos, mientras que los alumnos de quinto semestre tienden a elaborar frases en las que recurren a definirlos.

Tanto en primero como en quinto semestre se observa que los estudiantes presentan dificultad para escribir una frase alrededor del concepto solución sobresaturada y que, en ambos semestres para las categorías establecidas, los porcentajes de estudiantes ubicados en ellas no alcanzan el $50 \%$.

El par de conceptos, en el cual, los estudiantes de quinto semestre presentaron un mejor desempeño fue el integrado por los términos por protón y núcleo atómico, seguido por el de cambio químico y ecuación química. Los porcentajes de estudiantes que elaboraron correctamente una frase relacionando los términos dados en los pares fue mayor en quinto semestre que en primero; Por otra parte, tanto en el quinto como en el primer semestre el par de términos con los cuales los estudiantes presentaron dificultad para escribir una frase relacionándolos es el de equilibrio químico y constante de equilibrio.

En relación con la propuesta de un procedimiento de laboratorio para obtener oxígeno se estableció que, a pesar de presentarse un alto porcentaje de estudiantes que la 
respondieron, la mayoría de estas respuestas son incorrectas. A partir de las respuestas analizadas como propuestas, se establece que los estudiantes de ambos semestres aún confunden los cambios de estado del agua con una reacción química en la cual esta sustancia se puede separar sus componentes.

El análisis de los textos escritos por los estudiantes de ambos semestres permite establecer que un alto porcentaje de ellos se encuentra ubicado en el nivel $A$, ya que sus textos se limitan a la escritura de una frase en la que se tiene en cuenta una sola de las variables propuestas o son de naturaleza ambigua. El porcentaje de estudiantes de ambos semestres que alcanzan los niveles B y $\mathrm{C}$ son bajos, y los datos correspondientes al primer semestre son ligeramente mayores que los de quinto. Como era de esperarse, el porcentaje de estudiantes que llegan al nivel mas alto de producción de textos es del quinto semestre, aun cuando se trata de un porcentaje muy bajo.

\title{
BIBLIOGRAFÍA
}

AUSEBEL, D P. Psicología Educativa, Un Punto de Vista Cognitivo. Editorial Trillas. México, 1978.

CÁRDENAS, S. F. A. y MONTEALEGRE, R. R. Los Test de Asociación de Palabras y su Aplicación a la Evaluación en Química. Universidad de La Salle. Revista de investigación. No 1. Vol. 1. Octubre 2002.

CÁRDENAS S, F. A. Tópicos de mayor dificultad en Química: Posibles causas y Remedios. Actualidades Pedagógicas. Revista de la Facultad de Ciencias de la Educación. No. 42. P. 61-72. Universidad de La Salle. Bogotá, Noviembre 2000.

LADINO OSPINA YOLANDA. Un sistema de evaluación de competencias en química general para la educación superior. Tesis de doctorado en Educación: Área Educación en ciencias Naturales. Universidad Pedagógica Nacional. Bogotá. En Progreso.

\author{
ANEXO 1 \\ UNIVERSIDAD PEDAGOGICA NACIONAL \\ FACULTAD DE CIENCIA Y TECNOLOGIA \\ DEPARTAMENTO DE QUIMICA \\ PROYECTO DE GRADO: \\ “LOS TEST DE ASOCIACIÓN COMO MEDIO PARA DETERMINAR LA CAPACIDAD PARA \\ ESTABLECER RELACIONES ENTRE CONCEPTOS QUIMICOS"
}

FECHA

Semestre Académico 2002

El siguiente test forma parte del proyecto de investigación: LOS TEST DE ASOCIACIÓN COMO MEDIO PARA DETERMINAR LA CAPACIDAD PARA ESTABLECER RELACIONES ENTRE CONCEPTOS QUIMICOS, desarrollado por estudiantes del departamento de Química. Pretende establecer los niveles de comprensión de lectura de los estudiantes que cursan primer y quinto semestre en la Facultad de Ciencia y Tecnología.

1. Escriba una frase empleando cada uno de los siguientes términos y expresiones:

a. Sustancia

b. Compuesto

c. Cambio físico

d. Cambio químico

e. Solución sobresaturada

f. Calor

g. Temperatura 
2. Escriba una frase empleando en cada caso los siguientes pares de términos y expresiones:

a. Protón y núcleo atómico

b. Gases ideales y gases reales

c. Cambio químico y ecuación química

d. Equilibrio químico y constante de equilibrio

e. Mol y número de Avogadro

3. Describa un procedimiento práctico para obtener oxígeno en el laboratorio.

4. Lea el siguiente texto y luego realice el ejercicio solicitado.

La concentración de dióxido de carbono en la atmósfera, debida a la quema de combustibles fósiles, es uno de los mayores productos de desecho de la sociedad moderna y se ha incrementado en un $30 \%$ en la atmósfera desde la Revolución Industrial. Como resultado de este continuo incremento del dióxido de carbono, se ha producido un aumento de la temperatura promedio del planeta entre $1.5{ }^{\circ} \mathrm{C}$ y $4.5^{\circ} \mathrm{C}$. De 1900 a 1990, el aumento de la temperatura promedio de la Tierra ha sido progresivo.

Se predice que ese aumento traerá consigo la fusión de agua de los polos y el consecuente aumento del nivel del mar por lo menos en un metro para el año 2035. (Tomado de Química y ambiente I. Cárdenas Fidel y Gélvez Carlos, Ed. MacGraw Hill, 1996)

Teniendo en cuenta el contenido del párrafo y sus propios conocimientos, describa a continuación lo que piensa acerca de las relaciones entre contaminación atmosférica, combustibles fósiles y el desarrollo económico del mundo. 